\title{
Optimized Synthesis of Silver Nanoparticles by Factorial Design with Application for the Determination of Melamine in Milk
}

Dayana Borges Bittar, Tiago Augusto Catelani, Karina Nigoghossian, Hernane da Silva Barud, Sidney José Lima Ribeiro, Leonardo Pezza \& Helena Redigolo Pezza

To cite this article: Dayana Borges Bittar, Tiago Augusto Catelani, Karina Nigoghossian, Hernane da Silva Barud, Sidney José Lima Ribeiro, Leonardo Pezza \& Helena Redigolo Pezza (2017) Optimized Synthesis of Silver Nanoparticles by Factorial Design with Application for the Determination of Melamine in Milk, Analytical Letters, 50:5, 829-841, DOI: 10.1080/00032719.2016.1196213

To link to this article: https://doi.org/10.1080/00032719.2016.1196213

Jan 2017.

Published online: 12 Apr 2017.

Submit your article to this journal $\pi$

Щ Article views: 94

View Crossmark data $\subset$

Citing articles: 6 View citing articles $\llbracket \nearrow$ 


\title{
Optimized Synthesis of Silver Nanoparticles by Factorial Design with Application for the Determination of Melamine in Milk
}

\author{
Dayana Borges Bittar, Tiago Augusto Catelani, Karina Nigoghossian, \\ Hernane da Silva Barud, Sidney José Lima Ribeiro, Leonardo Pezza, and \\ Helena Redigolo Pezza \\ Instituto de Química, Universidade Estadual Paulista "Júlio de Mesquita Filho", Araraquara, São Paulo, Brazil
}

\begin{abstract}
A colorimetric method based on silver nanoparticles was developed for the determination of melamine in milk. Silver nanoparticles were synthesized without any stabilizer, using sodium borohydride as the reducing agent. Optimization of the variables for the formation of the nanoparticles was performed by factorial design, resulting in stable colloidal silver nanoparticles with a mean diameter of $14.0 \pm 2.7 \mathrm{~nm}$. Spectrophotometric measurements performed at $475 \mathrm{~nm}$ showed a linear range from 0.033 to $1.50 \mathrm{mg} \mathrm{L}^{-1}$ of melamine with limits of detection and quantification of 0.009 and $0.031 \mathrm{mg} \mathrm{L}^{-1}$, respectively. The method provided highly sensitive determination of melamine in milk.
\end{abstract}

\section{ARTICLE HISTORY}

Received 1 April 2016

Accepted 27 May 2016

\section{KEYWORDS}

Adulteration; colorimetry; melamine; milk; silver nanoparticles

\section{Introduction}

The adulteration of dairy products, especially milk, may represent a health risk to consumers. The organic compound melamine is one of many potential contaminants that can cause severe intoxication. Melamine (1,3,5-triazine-2,4,6-triamine, $\left.\mathrm{C}_{3} \mathrm{H}_{6} \mathrm{~N}_{6}\right)$ is widely used in the production of plastics, resins, coatings, and fertilizers, among other applications (Venkatasami and Sowa 2010). The majority of the molecular mass of the compound consists of nitrogen atoms, which probably explains the illegal incorporation of this substance in milk products by entrepreneurs and milk producers, to maximize profits (Panuwet et al. 2010). Incidents of melamine poisoning provide an example of hazards caused by economically motivated adulteration (Moore et al. 2010).

The ingestion of food containing high concentrations of melamine can lead to serious renal injury or even death. In 2008, melamine was detected in milk and other infant food products produced in China, as well as in dairy products manufactured in the US (Moore et al. 2010). This caused the cessation of trade in these food products and the loss of credibility among consumers and importing countries (Cassoli et al. 2011). After these episodes, regulators implemented stringent rules governing the maximum permissible levels of

CONTACT Helena Redigolo Pezza hrpezza@iq.unesp.br @ Instituto de Química, Universidade Estadual Paulista "Júlio de Mesquita Filho", R. Prof. Francisco Degni 55, P.O. Box 355, Araraquara, São Paulo 14800-900, Brazil.

Color versions of one or more of the figures in the article can be found online at www.tandfonline.com/lanl. 
melamine in milk. These are $2.5 \mathrm{mg} \mathrm{L}^{-1}$ in the USA and the European Union, and $1.0 \mathrm{mg} \mathrm{L}^{-1}$ for infant formulas in China (Zhu, Gamez et al. 2009).

Milk, the main dairy product, is a major dietary component consumed in many countries worldwide, and is therefore of considerable economic importance. Hence, it is essential that the food industry and regulatory agencies ensure the safety of milk and its derivatives consumed by the population.

The most common methods for protein measurement are the total determination of nitrogen by the Dumas or Kjeldahl techniques (Jung et al. 2003). Since these procedures measure total nitrogen in the sample, they are unable to distinguish protein-based nitrogen from nonprotein nitrogen.

The official method for melamine detection, specified by the Food and Drug Administration, uses gas chromatography-mass spectrometry, providing melamine quantification limits of between 0.05 and $10.0 \mathrm{mg} \mathrm{kg}^{-1}$ (Food and Drug Administration 2007). Various methods for the detection of melamine in milk products have been described in the literature. These include liquid chromatography with mass spectrometry (Goscinny et al. 2011), high-performance liquid chromatography (Ehling, Tefera, and Ho 2007; Sun et al. 2010), liquid chromatography with tandem mass spectrometry (Ge et al. 2011), gas chromatography with mass spectrometry (Zhu, Wang et al. 2009), capillary electrophoresis (Chang, Chu, and Tseng 2010), nuclear magnetic resonance (Lachenmeier et al. 2009), chemiluminescence analysis (Yokley et al. 2000), enzyme-linked immunosorbent assays (Wang et al. 2010), molecularly imprinted polymer-based sensors (Pietrzyk et al. 2009), matrix-assisted laser desorption/ionization mass spectrometry (Guo et al. 2011), and tandem mass spectrometry/low-temperature plasma probe (Zhu, Gamez et al. 2009).

However, most of these methods require the use of expensive equipment, while others are time consuming and laborious due to the complex pretreatment of samples, requiring extraction, purification, and derivatization, as well as other steps. There is therefore the need for a sensitive, rapid, and inexpensive screening method for the determination of melamine in food.

In recent years, interest in nanoparticles has increased due to their ability to improve the sensitivity of traditional analytical methods used for the detection of contaminants/ adulterants in food. The use of lanthanide-doped upconversion nanoparticles has been reported for the selective determination of melamine (Hazra, Adusumalli, and Mahalingam 2014). Several synthetic methods have been used to obtain nanoscale materials. The most widely used are chemical techniques based on reactions performed in solution, leading to the formation of colloids in which the nanoparticles are dispersed in a solvent (Oliveira et al. 2005; Araújo et al. 2012).

It is known that the interaction of metal ions with reducing substances, as well as the conditions and absorption by stabilization agents, strongly affects the size, stability, physicochemical properties, and morphology of metal nanoparticles (Knoll and Keilmann 1999; Chen et al. 2001; Sengupta et al. 2005). Silver nanoparticles are commonly synthesized in solution by reduction methods. These procedures require the use of reducing and stabilizing agents, which can be the same in some cases, such as sodium citrate (Henglein and Giersig 1999; Ping et al. 2012). The nature and concentration of reducing and stabilizing agents greatly influence the functional properties of silver nanoparticles (Ping et al. 2012). The use of stabilizing agents provides barriers that extend between the nanoparticles, hence increasing their stability. However, this type of protective coating 
can prevent the nanoparticles from reacting with certain analytes (such as melamine), hindering the detection (Neena, Devraj, and Bhagat 2012). Due to their extremely high extinction coefficients and strongly distance-dependent optical properties, silver nanoparticles have been used for the colorimetric detection of proteins (Ping et al. 2012), small molecules (Yang et al. 2014), ions, and melamine (Miao et al. 2013).

Melamine detection using silver nanoparticles synthesized with sodium citrate has been described previously (Ping et al. 2012). Song et al. (2014a) reported chromotropic acidmodified silver nanoparticles for the visual detection of melamine. Subsequently, Song et al. (2014b) studied silver nanoparticles modified with sulfanilic acid for the detection of the same analyte. Han and Li (2010) developed p-nitroaniline-modified silver nanoparticles for visual detection of melamine in infant formula. In all the studies described in the literature, the nanoparticles were synthesized in the presence of stabilizing agents.

The goal of the present work was to determine the optimized experimental conditions for the development of a simple and low-cost process for the production of stable silver nanoparticles. The use of factorial design was shown to be an important tool for increasing the sensitivity of the analytical method, enabling optimization of the concentrations of $\mathrm{AgNO}_{3}$ and $\mathrm{NaBH}_{4}$ used to obtain the silver nanoparticles, which has not been previously described in the literature. The nanoparticles were subsequently used for the determination of melamine in milk products at concentrations that may be harmful to human health.

The interaction between melamine amine groups and silver nanoparticles results in alteration in the surface plasmon resonance of the metal nanoparticles (Menon et al. 2012), which may be used for analytical purposes. After optimization of the experimental conditions for the synthesis of the silver nanoparticles by factorial design, the nanoparticles were characterized by ultraviolet/visible spectrophotometry and transmission electron microscopy. Evaluation was then made of the potential of the silver nanoparticles in the absence of stabilizers for the determination of melamine by ultraviolet/visible spectrophotometry.

\section{Experimental}

\section{Equipment and materials}

Absorbance measurements were performed using a spectrophotometer (Model HP 8453, Hewlett Packard) equipped with a cuvette $(b=1 \mathrm{~cm}$ ). An analytical balance (AG 204, Mettler Toledo) was used for weighing, and sample centrifugation used a refrigerated centrifuge (Universal $320 \mathrm{R}$, Hettich). An ultrasonic bath (Model T14, Thornton) was used to assist solubilization of the melamine solutions. Eppendorf micropipettes $(100-1000 \mu \mathrm{L})$ were used to deliver measured volumes in the experiments.

\section{Reagents and solutions}

All reagents were of analytical grade. Solutions were prepared in ultrapure water (18 $\mathrm{M} \Omega \mathrm{cm}$, Milli-Q system, Millipore). An aqueous melamine (Sigma Aldrich, 99\%) stock solution was prepared at a concentration of $1000 \mathrm{mg} \mathrm{L}^{-1}$ by solubilization of $100 \mathrm{mg}$ in deionized water in a $100-\mathrm{mL}$ volumetric flask with sonication for $10 \mathrm{~min}$. An intermediate $100 \mathrm{mg} \mathrm{L}^{-1}$ concentration of melamine was prepared by suitable dilution, and working standards were prepared in the range from 0.1 to $4.5 \mathrm{mg} \mathrm{L}^{-1}$. 
Working solutions of $\mathrm{AgNO}_{3}\left(3.00 \times 10^{-3} \mathrm{~mol} \mathrm{~L}^{-1}\right)$ and $\mathrm{NaBH}_{4}\left(1.25 \times 10^{-3} \mathrm{~mol} \mathrm{~L}^{-1}\right)$ were prepared by dilution of the corresponding $1.00 \times 10^{-1} \mathrm{~mol} \mathrm{~L}^{-1}$ stock solutions. Trichloroacetic acid solution $\left(3.0 \times 10^{-2} \mathrm{~g} \mathrm{~L}^{-1}\right)$ was used to precipitate the proteins in milk.

\section{Preparation of silver nanoparticles}

All glassware used for preparation of the silver nanoparticles were dipped in freshly prepared aqua regia $\left(\mathrm{HNO}_{3} / \mathrm{HCl}, 1: 3\right)$ and then rinsed thoroughly with deionized water to ensure removal of contaminants that may influence the synthesis of the nanoparticles. The silver nanoparticles were prepared by the borohydride reduction method with modifications (Creighton, Blatchford, and Albrecht 1979). Optimization of the variables $\left(\mathrm{NaBH}_{4}\right.$ and $\mathrm{AgNO}_{3}$ concentrations) was performed by experimental design methodology using central composite design with response surface. The Minitab 16 and Statistica 8.0 software packages were used for the multivariate analyses.

Under constant magnetic stirring, $6 \mathrm{~mL}$ of $1.25 \times 10^{-3} \mathrm{~mol} \mathrm{~L}^{-1} \mathrm{NaBH}_{4}$ was added to a beaker in an ice bath, followed by dropwise addition of $2 \mathrm{~mL}$ of $3.00 \times 10^{-3} \mathrm{~mol} \mathrm{~L}^{-1}$ $\mathrm{AgNO}_{3}$, producing a golden-yellow solution. At the end of the synthesis, the stirrer was switched off and the solution was transferred to a bottle protected from light, for storage in a refrigerator before the subsequent experiments. The synthesized silver nanoparticles were stable for at least 5 days when stored at $4.0 \pm 2.0^{\circ} \mathrm{C}$.

\section{Stability of the silver nanoparticles}

To study the effect of storage on the silver nanoparticles prepared in this work using the optimized variable values as well as silver nanoparticles prepared as described in the literature (Solomon et al. 2007), the nanoparticles were stored in the dark at $4.0 \pm 2.0^{\circ} \mathrm{C}$, in polypropylene bottles covered with aluminum foil. Absorbance measurements at $400 \mathrm{~nm}$ of the silver nanoparticle solutions were performed for 7 days.

\section{Preparation of milk}

Four milk samples (A-D) were used to evaluate the performance of the proposed method. The samples were purchased from a local market in Araraquara (São Paulo, Brazil).

Milk is a highly complex matrix, so the samples were pretreated using the method described by $\mathrm{Ni}$ et al. (2014) with modifications. $5 \mathrm{~mL}$ of fresh milk was placed in a centrifuge tube, followed by the addition of $1.5 \mathrm{~mL}$ of $3.0 \times 10^{-2} \mathrm{~g} \mathrm{~L}^{-1}$ trichloroacetic acid. After $1 \mathrm{~min}$ of manual shaking, the tube was sonicated for $10 \mathrm{~min}$ and centrifuged at $9.0 \times 10^{3} \mathrm{rpm}$ for $10 \mathrm{~min}$. The supernatant was heated to boiling to precipitate serum proteins (Fox and Mcsweeney 1998; Vasbinder et al. 2003). The supernatant was collected and passed through filter paper, and the $\mathrm{pH}$ was adjusted to 7.0 with $10 \mathrm{~mol} \mathrm{~L}^{-1} \mathrm{NaOH}$. The resulting solution was passed through a $0.22-\mu \mathrm{m}$ filter and diluted $25-\mathrm{d}$ before analysis.

\section{Calibration relationships}

After optimization of the variables by multivariate analysis, $300-\mu \mathrm{L}$ aliquots of melamine standard solutions at different concentrations were mixed with $600 \mu \mathrm{L}$ of silver 
nanoparticles, in triplicate, giving final melamine concentrations of $0.033,0.133,0.333$, $0.833,1.17$, and $1.50 \mathrm{mg} \mathrm{L}^{-1}$.

\section{Standard addition and recovery}

Standard addition was used to evaluate possible matrix interferences. Four liquid milk samples were used, fortified with melamine at 0.80 and $1.47 \mathrm{mg} \mathrm{L}^{-1}$. The fortified samples were pretreated as described for the milk samples, and were then analyzed by ultraviolet/ visible spectrophotometry at $475 \mathrm{~nm}$.

\section{Results and discussion}

Preliminary tests with silver nanoparticles synthesized with stabilizers (sodium citrate, ascorbic acid, and pectin) were performed with the goal of improving the sensitivity of the method for the determination of melamine in milk samples (Turkevich, Stevenson, and Hillier 1951; Fukuyo and Imai 2002; Nigoghossian et al. 2015). However, no positive results were obtained, possibly because the stabilization agents formed a protective coating that blocked interaction with the analyte of interest. Passivation or functionalization agents were not used, because the objective was to achieve direct interaction between the silver nanoparticles and the analyte. In the reported method, silver nanoparticles were therefore used in the absence of stabilization agents, which resulted in a significant increase in sensitivity.

\section{Stabilization of silver nanoparticles}

Silver nanoparticles are stabilized in aqueous solution by coating them with citrate ions (Pinto et al. 2010). In the same way, silver nanoparticles may be stabilized in aqueous solution by the adsorption of borohydride, which provides a surface charge surrounding the nanoparticle. Excess borohydride is needed to reduce the ionic silver and stabilize the silver nanoparticles. The nanoparticles are held in solution by repulsive electrostatic forces (Doty et al. 2005) between the particles due to the adsorbed borohydride. The use of excess of borohydride increases the overall ionic strength and promotes aggregation. Therefore, the quantity of borohydride must be sufficient to stabilize the nanoparticles without promoting aggregation.

\section{Central composite design}

Since only two variables were considered (the concentrations of $\mathrm{AgNO}_{3}$ and $\mathrm{NaBH}_{4}$ ), central composite design was the best approach for optimization of the procedure (Montgomery and Myers 2002). The values of the variables were studied using five levels, with four central points.

The minimum and maximum concentrations of the variables used to obtain the response surface were $\left(\mathrm{mol} \mathrm{L}^{-1}\right)$ : (1) $1.00 \times 10^{-3}$ and $5.00 \times 10^{-3}\left(\mathrm{AgNO}_{3}\right)$, and (2) $5.00 \times 10^{-4}$ and $2.00 \times 10^{-3}\left(\mathrm{NaBH}_{4}\right)$. Figure 1 shows the three-dimensional response surface graph obtained from the results. The quadratic regression model is described by:

$$
Z=-0.387+228.078 x-40928.125 x^{2}+876.613 y-368822.222 y^{2}+17666.667 x y,
$$



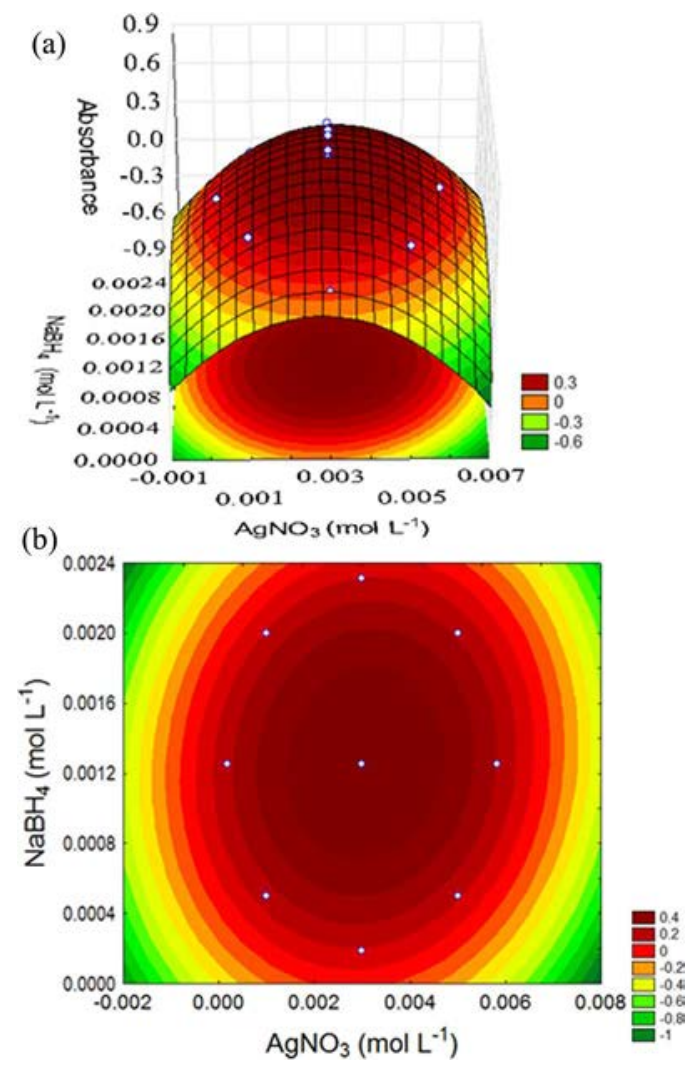

Figure 1. (a) Central composite design and (b) its projection based on absorbance measurements as functions of $\mathrm{AgNO}_{3}$ and $\mathrm{NaBH}_{4}$ concentrations.

where $Z$ is the response factor (corresponding to an absorbance value), and the factors $x$ and $y$ are the concentrations of $\mathrm{AgNO}_{3}$ and $\mathrm{NaBH}_{4}$, respectively. Figure 1 shows that the critical values (optimized variable values) for $\mathrm{AgNO}_{3}$ and $\mathrm{NaBH}_{4}$ were $3.00 \times$ $10^{-3} \mathrm{~mol} \mathrm{~L}^{-1}$ and $1.25 \times 10^{-3} \mathrm{~mol} \mathrm{~L}{ }^{-1}$, respectively. Therefore, an $\mathrm{AgNO}_{3} / \mathrm{NaBH}_{4}$ molar ratio of 1:1.25 was the best ratio for the minimum possible excess of sodium borohydride ensuring its stabilizing effect.

\section{Stability of the silver nanoparticles}

The stability of the silver nanoparticles using the optimized variable values $(2 \mathrm{~mL}$ of $3.00 \times 10^{-3} \mathrm{~mol} \mathrm{~L}^{-1} \mathrm{AgNO}_{3}$ and $6 \mathrm{~mL}$ of $1.25 \times 10^{-3} \mathrm{~mol} \mathrm{~L}^{-1} \mathrm{NaBH}_{4}$ ) was compared with those obtained using the synthesis conditions commonly described in the literature ( $1 \mathrm{~mL}$ of $1.00 \times 10^{-3} \mathrm{~mol} \mathrm{~L}^{-1} \mathrm{AgNO}_{3}$ and $3 \mathrm{~mL}$ of $2.00 \times 10^{-3} \mathrm{~mol} \mathrm{~L}^{-1} \mathrm{NaBH}_{4}$ ), where the $\mathrm{AgNO}_{3} / \mathrm{NaBH}_{4}$ molar ratio is $1: 6$. The latter condition uses an excess of sodium borohydride to reduce and stabilize the silver nanoparticles. However, the excess of $\mathrm{NaBH}_{4}$, when not optimized, increases the ionic strength of the system and causes aggregation of the nanoparticles (Solomon et al. 2007), which is undesirable for efficient interaction between the nanoparticles and the analyte. 


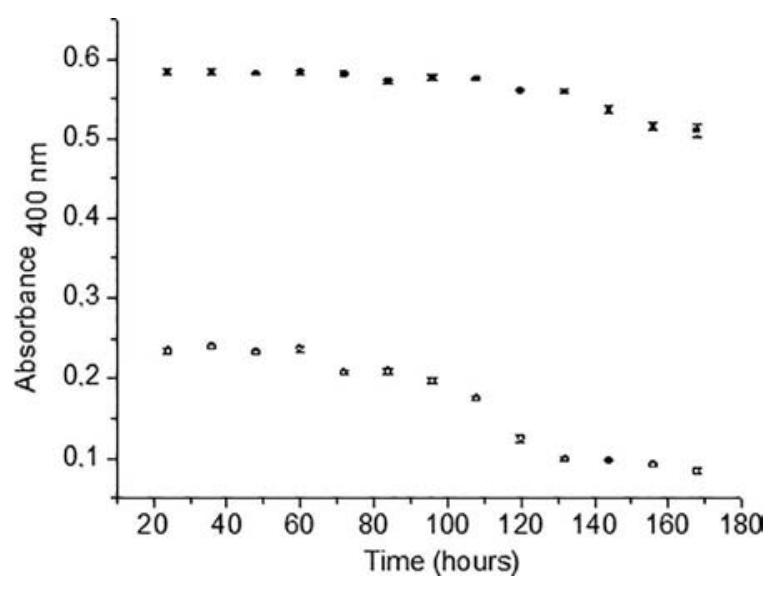

Figure 2. Absorbance as a function of time for the silver nanoparticles: ( $\square$ ) literature conditions using $1.00 \times 10^{-3} \mathrm{~mol} \mathrm{~L}^{-1} \mathrm{AgNO}_{3}, 2.00 \times 10^{-3} \mathrm{~mol} \mathrm{~L}^{-1} \mathrm{NaBH}_{4}$ and $(\boldsymbol{\square})$ this work using $3.00 \times 10^{-3} \mathrm{~mol} \mathrm{~L}^{-1}$ $\mathrm{AgNO}_{3}$ and $1.25 \times 10^{-3} \mathrm{~mol} \mathrm{~L}^{-1} \mathrm{NaBH}_{4}$. The absorbance was measured at $400 \mathrm{~nm}$ with a pathlength of $1 \mathrm{~cm}$.

The results in Figure 2 compare the changes in absorbance, as a function of the time, for the nanoparticles obtained by the synthesis procedures. The silver nanoparticles obtained using the optimized conditions showed higher stability and absorbance, indicating their suitability for use in the development of a highly sensitive spectrophotometric method for the quantification of melamine.

\section{Transmission electron microscopy and absorption spectra of silver nanoparticles}

It is well known that silver nanoparticles exhibit a yellow-brown color in aqueous solution, due to excitation of a surface plasmon resonance band in the ultraviolet/visible region (Hussain et al. 2011). The absorption spectrum of the stable silver nanoparticles showed a typical absorbance peak at $400 \mathrm{~nm}$ (Figure 3), indicating that the particles were well dispersed.

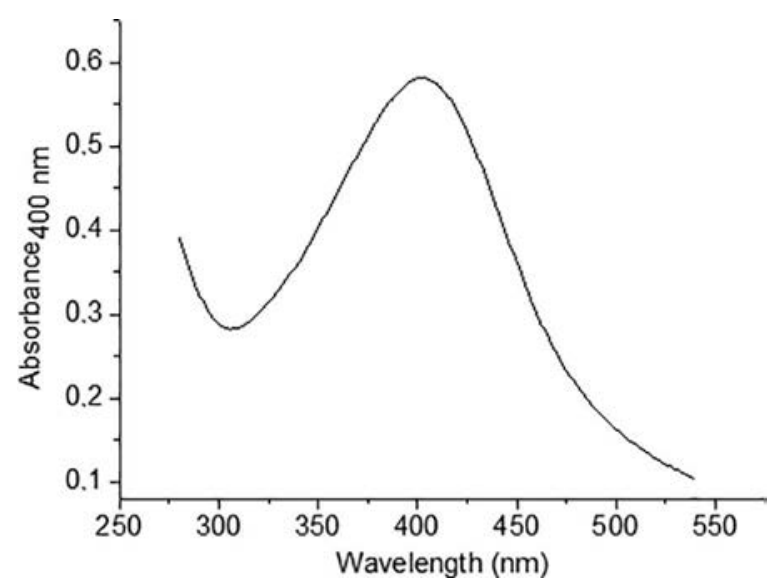

Figure 3. Absorption spectrum at $400 \mathrm{~nm}$ for silver nanoparticles in the absence of melamine. 
After the addition of melamine to the solution, silver nanoparticles were rapidly added and a color change of the solution was observed. Ping et al. (2012) reported that only the three amino groups of melamine are important in the interaction between melamine and silver nanoparticles, causing a rapid color change from yellow to red, while the threenitrogen hybrid ring makes no significant contribution. The transmission electron microscopy images of silver nanoparticles in the absence (Figure 4a) and in the presence (Figure $4 \mathrm{~b}$ ) of melamine (at a concentration of $1.50 \mathrm{mg} \mathrm{L}^{-1}$ ) showed clear evidence of particle aggregation (Figure $4 \mathrm{~b}$ ). The average size of the silver nanoparticles was determined using ImageJ software. Fifty nanoparticles were used for the calculation, and the average size found was $14.0 \pm 2.7 \mathrm{~nm}$.

\section{Analytical figures of merit}

The figures of merit of the analytical method evaluated included the limits of detection and quantification, precision, accuracy, and linear range. Under the optimized conditions, a linear response was obtained for melamine concentrations between 0.033 and $1.50 \mathrm{mg} \mathrm{L}^{-1}$. The linear equation obtained was: Absorbance $_{(475 \mathrm{~nm})}=0.385+0.155 x$ $C_{\text {melamine }}(R=0.999)$. Repeatability measurements using intraday and interday measurements of a $0.133 \mathrm{mg} \mathrm{L}^{-1}$ standard solution resulted in relative standard deviations less than $2.5 \%$.

The detection and quantification limits were determined according to IUPAC recommendations (Long and Winefordner 1983), using the expressions $3 \times(s / b)$ and $10 \times(s / b)$, respectively, where $s$ is the standard deviation of the points of the curve, and $b$ is the slope of the linear range. The calculated detection and quantification limits were 0.009 and $0.031 \mathrm{mg} \mathrm{L}^{-1}$, respectively. Figure 5 shows the analytical curves and the different colors of the silver nanoparticles. All measurements were performed at $475 \mathrm{~nm}$.

\section{Analysis of milk}

The effectiveness of the method was evaluated by the analysis of melamine in milk. Recovery assays were performed to determine the accuracy of the method and detect

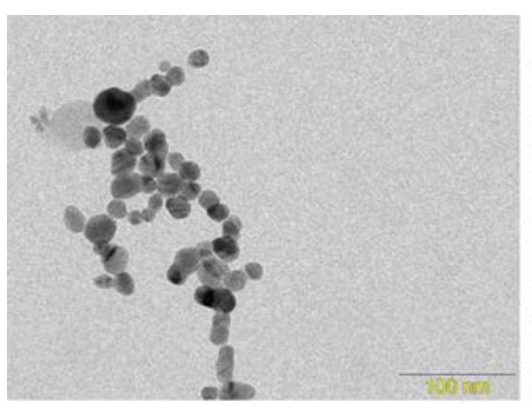

(a)

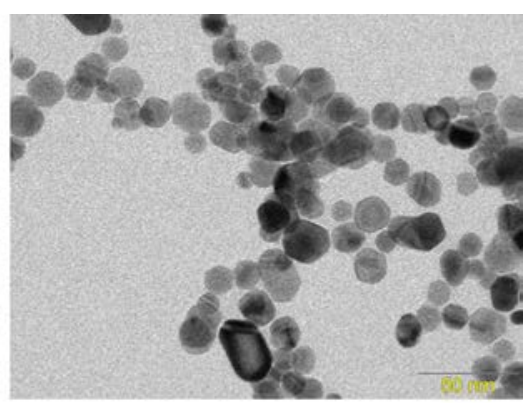

(b)

Figure 4. Transmission electron micrographs of silver nanoparticles in the (a) absence and (b) presence of $1.50 \mathrm{mg} \mathrm{L}^{-1}$ melamine. 
(a)

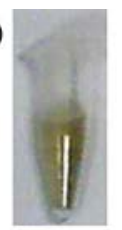

0.0333

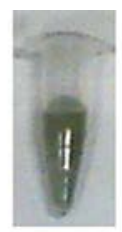

0.133

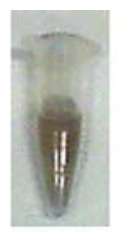

0.333

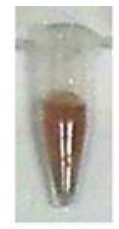

0.833

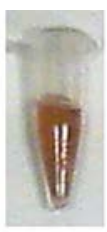

0.17

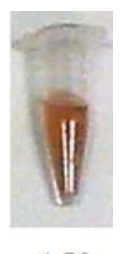

1.50

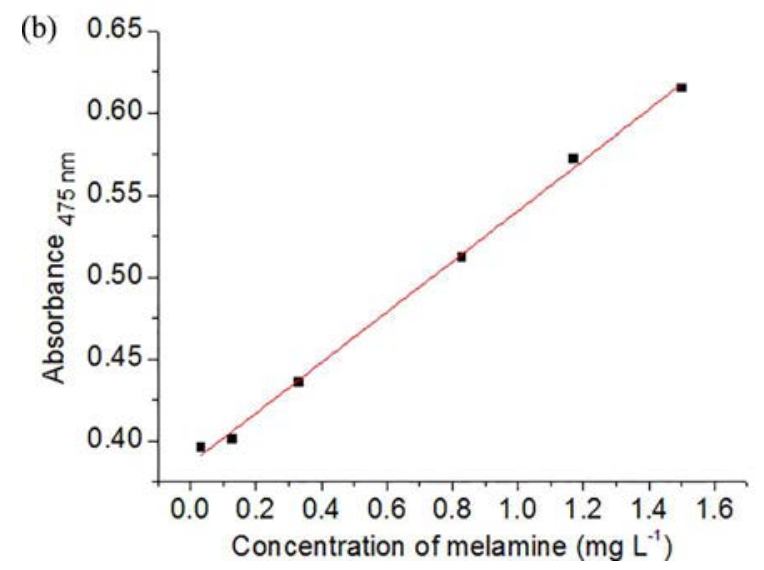

Figure 5. (a) Photographs of the nanoparticles at various melamine concentrations and (b) the calibration curve obtained using $0.033,0.133,0.333,0.833,1.17$, and $1.50 \mathrm{mg} \mathrm{L}^{-1}$ melamine.

possible matrix interferences. Samples spiked with melamine (Table 1) showed recoveries from 61.9 to $96.7 \%$, indicative of good accuracy and an absence of any major matrix effects in the method.

Compared to previously reported methods for the determination of melamine using silver nanoparticles, this approach provides a lower detection limit, as shown in Table 2. The increased sensitivity in the absence of protective agents suggests greater interaction between the silver nanoparticles and the amino groups of melamine compared to other methods. The use of protective agents provides barriers between the nanoparticles. The obtained results suggest that this protective coating prevents the nanoparticles from reacting with melamine, hindering the detection of the latter. Additional advantages of the new method are that sample preparation involves straightforward dilution and that the subsequent quantification was performed with portable equipment, enabling in situ analysis.

Table 1. Recovery of melamine in milk $(n=3)$.

\begin{tabular}{lccc}
\hline Sample & Added value $\left(\mathrm{mg} \mathrm{L}^{-1}\right)$ & Found value $\left(\mathrm{mg} \mathrm{L}^{-1}\right)$ & Recovery (\%) \\
\hline$A$ & 0.80 & $0.750 \pm 0.001$ & $93.8 \pm 0.1$ \\
& 1.47 & $1.160 \pm 0.003$ & $78.9 \pm 0.2$ \\
$B$ & 0.80 & $0.700 \pm 0.001$ & $87.5 \pm 0.1$ \\
& 1.47 & $0.910 \pm 0.003$ & $61.9 \pm 0.2$ \\
$C$ & 0.80 & $0.770 \pm 0.001$ & $96.3 \pm 0.1$ \\
& 1.47 & $0.950 \pm 0.003$ & $64.6 \pm 0.2$ \\
$D$ & 0.80 & $0.670 \pm 0.002$ & $83.8 \pm 0.3$ \\
& 1.47 & $0.920 \pm 0.002$ & $62.6 \pm 0.1$ \\
\hline
\end{tabular}


Table 2. Analytical figures of merit for this protocol and previously reported methods for the determination of melamine using silver nanoparticles.

\begin{tabular}{lccc}
\hline Method & $\begin{array}{c}\text { Linear dynamic } \\
\text { range }\left(\mathrm{mg} \mathrm{L}^{-1}\right)\end{array}$ & $\begin{array}{c}\text { Limit of } \\
\text { detection }\left(\mathrm{mg} \mathrm{L}^{-1}\right)\end{array}$ & Reference \\
\hline $\begin{array}{l}\text { Colorimetric with silver nanoparticles } \\
\begin{array}{c}\text { Colorimetric with label-free silver } \\
\text { nanoparticles }\end{array}\end{array}$ & - & 0.100 & Han and Li (2010) \\
Surface-enhanced Raman spectroscopy with & $0.50-21.4$ & 0.292 & Ping et al. (2012) \\
$\begin{array}{l}\text { silver nanoparticles } \\
\text { Raman spectroscopy with silver } \\
\quad \text { nanoparticles }\end{array}$ & $5.00-150$ & 0.010 & Zhang et al. (2010) \\
$\begin{array}{c}\text { Colorimetric with silver nanoparticles } \\
\text { without stabilizers }\end{array}$ & $0.033-1.50$ & 2.00 & $\begin{array}{c}\text { Rajapandiyan, Tang, and } \\
\text { Yang (2015) }\end{array}$ \\
\hline
\end{tabular}

\section{Conclusion}

A simple, rapid, and sensitive colorimetric method has been developed for the determination of melamine in milk, using its adsorption on the surfaces of silver nanoparticles by the amine groups. A simple synthesis of colloidal silver nanoparticles, without the need for any stabilization agent, was optimized by factorial design. The silver nanoparticles synthesized were stable for at least 5 days at $4.0 \pm 2.0^{\circ} \mathrm{C}$. The synthesis of silver nanoparticles without a colloid stabilizer likely resulted in a greater interaction between the silver nanoparticles and the amino groups of melamine, thereby increasing the sensitivity. The determination of melamine in commercial milk samples was demonstrated; therefore this approach offers a reliable and advantageous alternative to existing methods.

\section{Funding}

We would like to thank the Brazilian agencies CAPES and CNPq for financial support.

\section{References}

Araújo, E. A., N. J. Andrade, L. H. M. da Silva, P. C. Bernardes, Á. V. N. de C. Teixeira, J. P. N. de Sá, J. F. Q. Fialho Jr., and P. E. Fernandes. 2012. Antimicrobial effects of silver nanoparticles against bacterial cells adhered to stainless steel surfaces. Journal of Food Protection 4:701-705. doi:10.4315/0362-028x.jfp-11-276

Cassoli, L. D., B. Sartori, A. Zampar, and P. F. Machado. 2011. An assessment of Fourier transform infrared spectroscopy to identify adulterated raw milk in Brazil. International Journal of Dairy Technology 64:480-85. doi:10.1111/j.1471-0307.2011.00711.x

Chang, C. W., S. P. Chu, and W. L. Tseng. 2010. Selective extraction of melamine using 11-mercaptoundecanoic acid-capped gold nanoparticles followed by capillary electrophoresis. Journal of Chromatography A 1217:7800-806. doi:10.1016/j.chroma.2010.10.023

Chen, W., W. Cai, L. Zhang, G. Wang, and L. Zhang. 2001. Sonochemical processes and formation of gold nanoparticles within pores of mesoporous silica. Journal of Colloid and Interface Science 238:291-95. doi:10.1006/jcis.2001.7525

Creighton, J. A., C. R. Blatchford, and M. G. Albrecht. 1979. Plasma resonance enhancement of Raman scattering by pyridine adsorbed on silver or gold sol particles of size comparable to the excitation wavelength. Journal of the Chemical Society, Faraday Transactions 2: Molecular and Chemical Physics 75:790-98. doi:10.1039/f29797500790

Doty, R. C., T. R. Tshikhudo, M. Brust, and D. G. Fernig. 2005. Extremely stable water-soluble Ag nanoparticles. Chemistry of Materials 17:4630-35. doi:10.1021/cm0508017 
Ehling, S., S. Tefera, and I. P. Ho. 2007. High-performance liquid chromatographic method for the simultaneous detection of the adulteration of cereal flours with melamine and related triazine byproducts ammeline, ammelide, and cyanuric acid. Food Additives and Contaminants 24:1319-25. doi:10.1080/02652030701673422

Food, and Drug Administration. 2007. Interim melamine and analogues safety/risk assessment. http:// www.fda.gov/OHRMS/DOCKETS/98fr/07n-0208-ra00001.pdf (accessed February 23, 2015).

Fox, P. F., and P. L. H. McSweeney. 1998. Dairy chemistry and biochemistry. London, UK: Blackie Academic and Professional.

Fukuyo, T., and H. J. Imai. 2002. Morphological evolution of silver crystals produced by reduction with ascorbic acid. Journal of Crystal Growth 24:193-99. doi:10.1016/s0022-0248(02)00913-2

Ge, J., L. W. Zhao, C. Y. Liu, S. R. Jiang, P. W. Lee, and F. M. Liu. 2011. Rapid determination of melamine in soil and strawberry by liquid chromatography-tandem mass spectrometry. Food Control 22:1629-33. doi:10.1016/j.foodcont.2011.03.020

Goscinny, S., V. Hanot, J. F. Halbardier, J. Y. Michelet, and J. Van Loco. 2011. Rapid analysis of melamine residue in milk, milk products, bakery goods and flour by ultra-performance liquid chromatography/tandem mass spectrometry: From food crisis to accreditation. Food Control 22:226-30. doi:10.1016/j.foodcont.2010.04.032

Guo, Z. Y., P. P. Gai, T. T. Hao, S. Wang, D. Y. Wei, and N. Gan. 2011. Determination of melamine in dairy products by an electrochemiluminescent method combined with solid-phase extraction. Talanta 83:1736-41. doi:10.1016/j.talanta.2010.12.013

Han, C., and H. Li. 2010. Visual detection of melamine in infant formula at $0.1 \mathrm{ppm}$ level based on silver nanoparticles. Analyst 135:583-88. doi:10.1039/b923424a

Hazra, C., N. K. B. Adusumalli, and V. Mahalingam. 2014. 3,5-Dinitrobenzoic acid-capped upconverting nanocrystals for the selective detection of melamine. ACS Applied Materials \& Interfaces 6:7833-39. doi:10.1021/am5011089

Henglein, A., and M. Giersig. 1999. Formation of colloidal silver nanoparticles: Capping action of citrate. The Journal of Physical Chemistry B 103:9533-39. doi:10.1021/jp9925334

Hussain, J. I., S. Kumar, A. A. Hashmi, and Z. Khan. 2011. Silver nanoparticles: Preparation, characterization, and kinetics. Advanced Materials Letters 2:188-94. doi:10.5185/amlett.2011.1206

Jung, S., D. A. Rickert, N. A. Deak, E. D. Aldin, J. Recknor, L. A. Johnson, and P. A. Murphy. 2003. Comparison of Kjeldahl and Dumas methods for determining protein contents of soybean products. Journal of the American Oil Chemists' Society 80:1169-73. doi:10.1007/s11746-003-0837-3

Knoll, B., and F. Keilmann. 1999. Near-field probing of vibrational absorption for chemical microscopy. Nature 399:134-37.

Lachenmeier, D. W., E. Humpfer, F. Fang, B. Schütz, P. Dvortsak, C. Sproll, and M. Spraul. 2009. NMR-spectroscopy for nontargeted screening and simultaneous quantification of health-relevant compounds in foods: The example of melamine. Journal of Agricultural and Food Chemistry 57:7194-99. doi:10.1021/jf902038j

Long, G. L., and J. D. Winefordner. 1983. Limit of detection: A closer look at the IUPAC definition. Analytical Chemistry 55:712A-24A. doi:10.1021/ac00258a724

Menon, S. K., B. R. Mistry, K. V. Joshi, P. G. Sutariya, and R. V. Patel. 2012. Analytical detection and method development of anticancer drug Gemcitabine $\mathrm{HCl}$ using gold nanoparticles. Spectrochimica Acta Part A: Molecular and Biomolecular Spectroscopy 94:235-42. doi:10.1016/j. saa.2012.02.061

Miao, P., T. Liu, X. Li, L. Ning, J. Yin, and K. Han. 2013. Highly sensitive, label-free colorimetric assay of trypsin using silver nanoparticles. Biosensors and Bioelectronics 49:20-24. doi:10.1016/j. bios.2013.04.038

Montgomery, D. C., and R. H. Myers. 2002. Response surface methodology: Process and product optimization using design experiments, 2nd ed. New York, US: Wiley.

Moore, J. C., J. W. DeVries, M. Lipp, J. C. Griffiths, and D. R. Abernethy. 2010. Total protein methods and their potential utility to reduce the risk of food protein adulteration. Comprehensive Reviews in Food Science and Food Safety 9:330-57. doi:10.1111/j.1541-4337.2010.00114.x

Neena, D., K. M. Devraj, and A. P. Bhagat. 2012. Role of capping agent in the synthesis of silver nanoparticles. Journal of Pharmacy Research 5:4710-12. 
Ni, P., H. Dai, Y. Wang, Y. Sun, Y. Shi, J. Hu, and Z. Li. 2014. Visual detection of melamine based on the peroxidase-like activity enhancement of bare gold nanoparticles. Biosensors and Bioelectronics 60:286-91. doi:10.1016/j.bios.2014.04.029

Nigoghossian, K., M. V. dos Santos, H. S. Barud, R. R. da Silva, L. A. Rocha, J. M. A. Caiut, R. M. N. de Assuncão, L. Spanhel, M. Poulain, Y. Messaddeq, and S. J. L. Ribeiro. 2015. Orange pectin mediated growth and stability of aqueous gold and silver nanocolloids. Applied Surface Science 341:28-36. doi:10.1016/j.apsusc.2015.02.140

Oliveira, M. M., D. Ugarte, D. Zanchet, and A. J. G. Zarbin. 2005. Influence of synthetic parameters on the size, structure, and stability of dodecanethiol-stabilized silver nanoparticles. Journal of Colloid and Interface Science 292:429-35. doi:10.1016/j.jcis.2005.05.068

Panuwet, P., E. L. Wade, J. V. Nguyen, M. A. Montesano, L. L. Needham, and D. B. Barr. 2010. Quantification of cyanuric acid residue in human urine using high performance liquid chromatography-tandem mass spectrometry. Journal of Chromatography B 878:2916-22. doi:10.1016/j. jchromb.2010.08.019

Pietrzyk, A., W. Kutner, R. Chitta, M. E. Zandler, F. D’Souza, F. Sannicolo, and P. R. Mussini. 2009. Melamine acoustic chemosensor based on molecularly imprinted polymer film. Analytical Chemistry 81:10061-70. doi:10.1021/ac9020352

Ping, H., M. Zhang, H. Li, S. Li, Q. Chen, C. Sun, and T. Zhang. 2012. Visual detection of melamine in raw milk by label-free silver nanoparticles. Food Control 23:191-97. doi:10.1016/j. foodcont.2011.07.009

Pinto, V. V., M. J. Ferreira, R. Silva, H. A. Santos, F. Silva, and C. M. Pereira. 2010. Long time effect on the stability of silver nanoparticles in aqueous medium: Effect of the synthesis and storage conditions. Colloids and Surfaces A: Physicochemical and Engineering Aspects 364:19-25. doi:10.1016/ j.colsurfa.2010.04.015

Rajapandiyan, P., W. L. Tang, and J. Yang. 2015. Rapid detection of melamine in milk liquid and powder by surface-enhanced Raman scattering substrate array. Food Control 56:155-60. doi:10.1016/j.foodcont.2015.03.028

Sengupta, S., D. Eavarone, I. Capila, G. Zhao, N. Watson, T. Kiziltepe, and R. Sasisekharan. 2005. Temporal targeting of tumour cells and neovasculature with a nanoscale delivery system. Nature 436:568-72. doi:10.1038/nature03794

Solomon, S. D., M. Bahadory, A. V. Jeyarajasingam, S. A. Rutkowsky, C. Boritz, and L. Mulfinger. 2007. Synthesis and study of silver nanoparticles. Journal of Chemical Education 2:322-25. doi:10.1021/ed084p322

Song, J., F. Wu, Y. Wan, and L. H. Ma. 2014a. Visual test for melamine using silver nanoparticles modified with chromotropic acid. Microchimica Acta 181:1267-74. doi:10.1007/s00604-014$1227-4$

Song, J., F. Wu, Y. Wan, and L. H. Ma. 2014b. Colorimetric detection of melamine in pretreated milk using silver nanoparticles functionalized with sulfanilic acid. Food Control 50:356-61. doi:10.1016/ j.foodcont.2014.08.049

Sun, H. W., L. X. Wang, L. F. Ai, S. X. Liang, and H. Wu. 2010. A sensitive and validated method for determination of melamine residue in liquid milk by reversed phase high-performance liquid chromatography with solid-phase extraction. Food Control 21:686-91. doi:10.1016/j. foodcont.2009.10.008

Turkevich, J., P. C. Stevenson, and J. Hillier. 1951. A study of the nucleation and growth processes in the synthesis of colloidal gold. Discussions of the Faraday Society 11:55-75. doi:10.1039/ df9511100055

Vasbinder, A. J., A. C. Alting, R. W. Visschers, and C. G. de. Kruif. 2003. Texture of acid milk gels: Formation of disulfide cross-links during acidification. International Dairy Journal 13:29-38. doi:10.1016/s0958-6946(02)00141-3

Venkatasami, G., and J. R. Sowa Jr. 2010. A rapid, acetonitrile-free, HPLC method for determination of melamine in infant formula. Analytica Chimica Acta 665:227-30. doi:10.1016/j.aca.2010.03.037

Wang, Z. Y., X. Ma, L. Y. Zhang, W. J. Yang, L. M. Gong, P. L. He, and Z. Li. 2010. Screening and determination of melamine residues in tissue and body fluid samples. Analytica Chimica Acta 662:69-75. doi:10.1016/j.aca.2010.01.004 
Yang, N., Y. Gao, Y. Zhang, Z. Shen, and A. Wu. 2014. A new rapid colorimetric detection method of $\mathrm{Al}^{3+}$ with high sensitivity and excellent selectivity based on a new mechanism of aggregation of smaller etched silver nanoparticles. Talanta 122:272-77. doi:10.1016/j.talanta.2014.01.035

Yokley, R. A., L. C. Mayer, R. Rezaaiyan, M. E. Manuli, and M. W. Cheung. 2000. Analytical method for the determination of cyromazine and melamine residues in soil using LC-UV and GC-MSD. Journal of Agricultural and Food Chemistry 48:3352-58. doi:10.1021/jf991231w

Zhang, X., M. Zou, X. Qi, F. Liu, X. Zhu, and B. Zhao. 2010. Detection of melamine in liquid milk using surface-enhanced Raman scattering spectroscopy. Journal of Raman Spectroscopy 41:165560. doi:10.1002/jrs.2629

Zhu, L., G. Gamez, H. Chen, K. Chingin, and R. Zenobi. 2009. Rapid detection of melamine in untreated milk and wheat gluten by ultrasound-assisted extractive electrospray ionization mass spectrometry (EESI-MS). Chemical Communications 5:559-61. doi:10.1039/b818541g

Zhu, X. L., S. H. Wang, Q. Liu, Q. Xu, S. X. Xu, and H. L. Chen. 2009. Determination of residues of cyromazine and its metabolite, melamine, in animal-derived food by gas chromatography-mass spectrometry with derivatization. Journal of Agricultural and Food Chemistry 57:11075-80. doi:10.1021/jf902771q 